\section{Visual impairment and the risk of mortality: addressing complex associations}

\author{
Alison Bruce
}

The worldwide rise in the ageing population has led to increasing levels of visual impairment. ${ }^{1}$ Visual impairment impacts on the individual with the potential to lead to loss of independence, falls, depression and reduced functional ability, and at a population level, there is an impact on the delivery of public health resources. ${ }^{1-3}$ Not only does visual impairment impact on morbidity, its impact on the risk of mortality has also been reported; it is important therefore to understand its effect at an individual and population level. In this issue of Journal of Epidemiology and Community Health, Zhang et $a l^{4}$ report the results of a meta-analysis investigating the association between visual impairment and mortality.

Several population-based studies have investigated the association between visual impairment and mortality, however not all studies have demonstrated comparable findings. The Beaver Dam Eye Study reported increased mortality associated with visual impairment and dense cataract over a 5 -year period even after controlling for age and gender. ${ }^{5}$ The Blue Mountains Eye Study also reported an association between cataract, visual impairment and increased mortality after a 5-year follow-up; ${ }^{6}$ however, after 11 years, the association between mortality and visual impairment was no longer significant. ${ }^{7}$ At the 13-year follow-up, an association between visual impairment and risk of mortality was again demonstrated, particularly in visually impaired participants younger than 75 years. ${ }^{8}$ Kuang et $a l^{9}$ investigated the association between visual impairment and mortality over a 3-year period in a population-based study of participants over the age of 65 years in Taiwan. No association between visual impairment and mortality was found.

In the Canadian Study of Health and Aging (CSHA), which reported mortality over a 5-year period, although vision showed an association with mortality in unadjusted analysis, the association

Correspondence to Dr Alison Bruce, Bradford Institute for Health Research, Duckworth Lane, Bradford BD9 6RJ, UK; alison.bruce@bthft.nhs.uk disappeared in the multivariate analysis which controlled for factors such as heart disease, stroke, diabetes and hearing problems. ${ }^{10}$ Kulmala and colleagues found reduced visual acuity predicted mortality in younger (75 years) but not in older participants (80 years). In their analysis, they took into account the participants walking speed, physical ability, accidents, diabetes, cardiovascular disease and depression. ${ }^{11}$

Gender difference has been reported with the Salisbury Eye Evaluation Project in the USA reporting women to have an increased risk of mortality in the presence of visual impairment, an association which was not found in men. ${ }^{12}$ Lee and colleagues report the result of the National Health Interview Survey (NHIS); this is a continuous survey of adults over the age of 18 years residing in the USA. Self-reported data were provided via a questionnaire, and mortality data were examined over an 8-year period. They reported an association with severe bilateral visual impairment and to some extent low levels of visual impairment, particularly in women.

Improving the level of visual acuity has been shown to reduce the risk of mortality. Freeman et $a l^{12}$ report that surgical intervention to remove cataract subsequently improving visual acuity by two lines or more reduced the risk of mortality. Similar findings were reported from the Blue Mountains Eye Study, which after adjusting for all covariates found a lower risk of mortality where there was improved vision postcataract extraction. ${ }^{8}$

Age is the major determinant of mortality. The age range differs between studies with adults from 18 years of age included in one study ${ }^{13}$ and others varying recruitment age from $40^{14}$ to over 80 years of age. ${ }^{12}$ All the cohort studies reporting visual impairment and mortality account for age in the analysis; however, many of the eye conditions that lead to visual impairment are age related, that is, age-related macular degeneration (ARMD), glaucoma and cataract. Eye conditions such as diabetic retinopathy and retinal vein occlusion are also associated with systemic conditions such as diabetes and cardiovascular disease and may reflect the impact of that particular disorder.

There is significant diversity between the design of the reported studies, method of recruitment, length of follow-up, age of the participants, ethnicity, measure of vision and definition of visual impairment. Many studies include participants with specific age-related conditions such as cataract, diabetic retinopathy and ARMD. The potential for bias within these observational studies is therefore high. Meta-analyses provide the potential to aid our understanding of the sources of variation occurring between studies. The meta-analysis presented by Zhang et $a l^{4}$ takes into account the sources of variability across studies and also further uses the reported data to quantify levels of visual impairment providing an estimate of the dose response between visual acuity and the risk of mortality. The meta-analysis provides confirmation of an association between visual impairment and the risk of mortality; further research is now warranted to investigate the association of the different risk factors including the interaction between specific eye conditions and systemic disease to determine whether the cause of the visual impairment, the eye condition or the disease process itself, is associated with increased mortality.

Funding $A B$ is funded by a National Institute for Health Research Post-Doctoral Fellowship Award (PDF2013-06-050).

Disclaimer The views expressed are those of the author and not necessarily those of the NHS, the NIHR or the Department of Health.

Competing interests None declared.

Provenance and peer review Commissioned; internally peer reviewed.

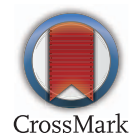

To cite Bruce A. J Epidemiol Community Health 2016;70:746-747.

Published Online First 9 May 2016

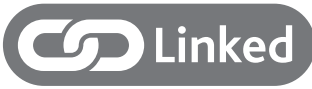

http://dx.doi.org/10.1136/jech-2016-207331

J Epidemiol Community Health 2016;70:746-747. doi:10.1136/jech-2016-207580

\section{REFERENCES}

1 Bourne RR, Stevens GA, White RA, et al., Vision Loss Expert Group. Causes of vision loss worldwide, 1990-2010: a systematic analysis. Lancet Glob Health 2013;1:e339-49. 
2 Rubin GS, Roche KB, Prasada-Rao P, et al. Visual impairment and disability in older adults. Optom Vis Sci 1994;71:750-60.

3 van der Aa HP, van Rens GH, Comijs HC, et al. Stepped care for depression and anxiety in visually impaired older adults: multicentre randomised controlled trial. BMJ 2015;351: h6127.

4 Zhang $T$, Jiang $W$, Song $X$, et al. The association between visual impairment and the risk of mortality: a meta-analysis of prospective studies. J Epidemiol Community Health 2016;70:836-42.

5 Klein R, Klein BE, Moss SE. Age-related eye disease and survival. The Beaver Dam Eye Study. Arch Ophthalmol 1995;113:333-9.
6 Wang JJ, Mitchell P, Simpson JM, et al. Visual impairment, age-related cataract, and mortality. Arch Ophthalmol 2001;119:1186-90.

7 Cugati S, Cumming RG, Smith W, et al. Visual impairment, age-related macular degeneration, cataract, and long-term mortality: the Blue Mountains Eye Study. Arch Ophthalmol 2007;125:917-24.

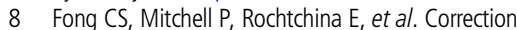
of visual impairment by cataract surgery and improved survival in older persons: the Blue Mountains Eye Study cohort. Ophthalmology 2013;120:1720-7.

9 Kuang TM, Tsai SY, Liu CJL, et al. The association of visual impairment and 3-year mortality among the elderly in Taiwan: the Shihpai Eye Study. J Chin Med Assoc 2015;78:177-81.
10 Ostbye T, Steenhuis R, Wolfson C, et al. Predictors of fiveyear mortality in older Canadians: the Canadian Study of Health and Aging. J Am Geriatr Soc 1999;47:1249-54.

11 Kulmala J, Era P, Törmäkangas T, et al. Visual acuity and mortality in a rural adult population (the Southern Harbin eye study). Ophthalmic Epidemiol 2011;15:54-60.

12 Freeman EE, Egleston BL, West SK, et al. Visual acuity change and mortality in older adults. Invest Ophthalmol Vis Sci 2005;46:4040-5.

13 Lee DJ, Gómez-Marín O, Lam BL, et al. Visual acuity impairment and mortality in US adults. Arch Ophthalmol 2002;120:1544-50.

14 McCarty CA, Nanjan MB, Taylor HR. Vision impairment predicts 5 year mortality. $\mathrm{Br} \mathrm{J}$ Ophthalmol 2001;85:322-6. 